\title{
An Ethical Approach to the Concept of Toleration: Understanding Tolerance as a Political Virtue
}

\author{
Ivón Cepeda Mayorga \\ National School of Postgraduate in Humanities and Social Sciences, Tecnológico de Monterrey, Campus Santa \\ Fe, Mexico City, Mexico \\ Email: icepeda@itesm.mx
}

Received 27 August 2014; revised 24 September 2014; accepted 12 October 2014

Copyright @ 2014 by author and Scientific Research Publishing Inc.

This work is licensed under the Creative Commons Attribution International License (CC BY). http://creativecommons.org/licenses/by/4.0/

(c) (i) Open Access

\begin{abstract}
The concept of toleration is commonly argued in political discourses and debates, when people refer to diversity and pluralism, as a form of respect and understanding. However, this does not represent an improvement at the moment of dealing with issues where a variety of values, conceptions and beliefs arises. In addition, even though when the idea of toleration was developed during Enlightenment, nowadays it seems to lead to a misconception of the term, following a connotation of a passive indifference about diversity. Due to this, the main objective of this text is to analyze the concept of toleration from an ethical perspective that allows thinking about it in terms of a political virtue needed to face the challenges of diversity inside society. In order to show this, the text presents an analysis of different conceptions of the term, in order to highlight the positive notion of toleration; after that, the text moves on, reviewing the idea of toleration from a hermeneutical perspective, as a form to reinforce the positive characteristics of the term, and path to solve the query between tolerance and intolerance. Finally, as a conclusion, it underlines that understanding the concept of toleration from an ethical perspective implies a praxis develop in daily circumstances.
\end{abstract}

\section{Keywords}

Positive Toleration, Hermeneutics, Political Virtue, Carlos Thiebaut, Hans-Georg Gadamer

\section{Introduction}

Toleration, as a concept has become a common place in the rhetoric of politicians as one virtue needed to im- 
prove democratic regimes, especially societies hit by any form of authoritarianism. The concept of toleration arose within political philosophy during the Enlightenment, as a response to the religious wars that took place at that time. Some authors, such as Locke and Voltaire, highlighted the importance of toleration as a virtue needed to underpin the structure of the Modern State as a political institution, which should be independent of any religious institution or pressure. Furthermore, Mill's theory of liberty added an important element to meaning of toleration. His thought is based on the search for truth conducted through open and public discourse of the different arguments circulating within society. These concepts: toleration, respect and liberty, were taken as the values to be defended in democratic liberal political regimes. However, in recent times, the concept of toleration has been the target of several criticisms which argue that toleration itself has become medium for imposing and strengthening certain political regimes which promote specific economic, social and political policies, instead of allowing for debate between different perspectives and points of view. This has led to a misconception about what toleration means and what it demands from us.

This text explores the concept of toleration from an ethical perspective. The main question that will guide the whole reflection is if through an ethical perspective is possible to develop an understanding of the concept of toleration, which implies a difference from a notion of a passive indifference. Then, my aim is to provide an insight of the term as a political virtue, which demands a full understanding of the concept as a constructive path to recognition and dialogue, and not only a path of respect. In order to accomplish this, I will analyze: 1) two different conceptions of toleration: positive toleration and negative toleration, as two different kinds of attitudes. In this part I will primarily analyze the argument of Carlos Thiebaut; 2) by using Hans-George Gadamer's theory of hermeneutics as a complement to the concept of positive toleration, and thereby supporting recognition and dialogue with the other as a way to understand the other and ourselves; and 3) the complementary relationship between tolerant and intolerant attitudes as a way to establish limits to toleration itself.

The text concludes showing that, while toleration is already considered a political virtue, an ethical understanding of the term must be developed with the aim of fully understanding its implications within a contemporary heterogenous society, as most of our societies are. This part, finally shows how we not only need to know the meaning of the term, but also to form in people a certain understanding of toleration which demands a great deal of responsibility so as to be considered as a virtue within our political life.

\section{The Origins of the Concept: Toleration as a Claim of Freedom and Respect}

It is said that, mostly, people start to think and promote tolerance as a worthy attitude (or even a political virtue) while they pass through a period of intolerance and violent acts. In order to understand criticisms and questions that are imposed to the concept of toleration, it is important to recognize the principal ideas that this concept tries to highlight since its origins. Even when we can trace some tolerant attitudes back to Rome and some periods of the Middle Ages, the concept of tolerance arose as part of a political and philosophical approach at the periods of Reformation and Counter-Reformation. At that time, Europe was facing one of the cruelest persecutions of people due to the radical intolerance displayed towards those with different religions, and who did not conform to the dictates of the day. Thus, it is important to recognize that philosophers started to consider tolerance as a valuable attitude while Europe was embroiled in deeply intolerant religious disputes in various places.

Certainly, this text is not focused in reviewing the concept of tolerance through an historical approach; however, I consider that it is important to understand the ideals that have surrounded the concept of toleration, as a form to advance some issues that are faced today. As Philippe Sassier states in his book, Porquoi la tolerance (Sassier, 2002), the attitude of being tolerant has being accompanied by different objectives along all its history. During the Middle Ages, some writers as Augustine of Hippo or Erasmus of Rotterdam defend a tolerant attitude against those who practice different beliefs from the Catholic Church, as a command of piety and mercy from God. In a sense, people were asked to be tolerant as a way to obey God and secure his blessings and glory during this life and whatever comes after death (Sassier, 2002). This helped to ensure the political domain that the Catholic Church had at that time.

Therefore, in a sense, the defense of Luther for a free interpretation of the Holy Texts was also perceived as a movement that leaded to establish the limits of the political power that every religious institution should have within a society. Some emblematic authors like Spinoza, Locke and Rousseau, following their particular perspectives, addressed that religious beliefs were part of a private domain that should be only regulated by the same individuals; on the other hand, all public issues considered as political ones, were supposed to be independent on 
any religious institution but on the State as a political entity (Camps, 1996). In this sense, the concept of toleration was conceived as a way to settle apart the distinction of what should be considered as private issues and what should be considered as public ones. These public concerns were, then, only proper of political institutions and States.

Later on, John Stuart Mill with his defense of free speech pointed out the importance of the individual liberty. His reflection was primarily focused on the idea that there is not an absolute truth, and that, in any case, the truth should be conformed through debate and discussion of different ideas and opinions (Mill, 1999). This will lead us to establish a distinction of which is considered as a truth-claim or a validity-claim, a point that will be considered at the defining moment of toleration. In the meantime, following Mill's arguments, he specially emphasized that every person should develop their own idea of truth. This can be conceived as an approach to respect other people in order to allow them to find their own explanation and concept of truth. Here, it is important to note then that the concept of tolerance appears at the same time as other characteristic ideas of the modern society, such as freedom, respect, and autonomy.

In accordance with this line of thought, respect and freedom are perceived as two concepts that have a close relation with the idea of tolerance. Especially in some discourses, tolerance is thought to imply only the idea of respect; nevertheless, both concepts arouse different approaches to the dilemma of diversity of thoughts and beliefs. As a way to clarify this distinction, firstly it is important to understand in a deep sense the meaning, the misty points and the limits of the concept of tolerance.

\section{Different Approaches to the Idea of Toleration: The Importance of Emphasizing Toleration as a Positive Practice}

One of the principal dilemmas with defining the concept of toleration is that it could lead to different meanings and distant approaches: on the one hand it is used to express a passive attitude of putting up with an idea, practice, or group while not really supporting it. This version of tolerance is usually adopted as a form of indifference towards different ideas. On the other hand, toleration also implies an active attitude of respect and recognition of other perspectives and arguments. This is the positive notion of toleration, one which can lead to more constructive discussions identified with the use of claims of validity, instead of claims of truth, associated with certain ideas, practices, and beliefs.

The dilemma lies within the concept of tolerance itself; there is a certain ambiguity between the idea of bearing something, and the act of trying to understand and even sympathize with it. In fact, it is my assertion that the negative connotations associated with the term "tolerance" derive from this ambiguity. Tolerance is derived from the Latin term tolerantia-ae, wherein the emphasis is placed on the idea of bearing, or putting up with something. But there is also a more positive understanding that completes the idea I am trying to defend in this paper. The positive dimension of tolerance which can be found in the original Latin usage includes patience, respect and recognition of the other. This recognition of the other is what gives sense to tolerance as an ethical principle. As such, tolerance enables the possibility to establish a process of critical reflection and dialogue between distinct participants and ideas. For this reason, it becomes crucial to understand this distinction between a positive and a negative reading of the term, it is only through the use of the positive dimension that we are able to visualize the possibilities for a positive tolerance within a diverse environment.

Attempts have been made to bring this version of tolerance to light and practice. According to Carlos Thiebaut, positive tolerance can be understood as "the movement that promotes interest and understanding of different forms of the human condition” (Thiebaut, 1999: p. 42). This reading of tolerance is based on acknowledging the other which "modifies the forms in which we understand the different one and, after all, the ways we understand ourselves" (Thiebaut, 1999: p. 59). This idea where I not only attempt to understand the other, but I also learn something more about myself, or the human condition, is highly hermeneutic insofar as it requires of us an act of interpretation. The very attempt to interpret and understand leads to a dual level of understanding; of the other and of myself. In this sense tolerance becomes a principle for coexistence that originates in the relationship between two people/groups/cultures. Further, tolerance is not contained by personal individual behavior, rather it is enacted in relation to and with another person or group. The manner in which we respond to the interaction is what delimits the positive or negative form of our tolerance. Similarly, the kind of relationship that is possible between myself and the other is determined by the form of tolerance we exercise in a given moment of interpretation and understanding. As Todorov explains in Frente al limite: "Talking with somebody and, in particular, 
talking about him, implies that I recognize in myself some kind of kinship with that person even when my words are, in their true meaning, incompatible with his” (Todorov, 1993: p. 285).

Another way to determine the differences between various forms of tolerance is to consider the idea in terms of degrees of tolerance by which relationships between individuals or social groups can be understood (Waldron, 1993). The first degree of tolerance is similar to what we have termed negative tolerance. Here we find the expression of tolerance within a community or environment composed of various groups to be a matter of putting up with each other if, and only if, there is no concrete relationship between the various groups. That is, they apparently ignore each other to the greatest extent possible, and when interaction is required, the relationship remains one of mutual indifference. We find it in the constitution of ghettos or neighborhoods, wherein each group is aware of the other but they refrain from actually developing inter-groupal relationships. This distance is usually maintained by social norms and restrictions for those who do have contact with the other group.

The second degree of tolerance, which tends to be a limited tolerance, is found in situations where various groups interact in a given space or community and there is tolerance but only to a certain point. In this case there is positive interaction and even the possibility of forming relationships, but certain topics are not open for discussion or connection between members of separate groups. Generally speaking, the untouchable topics are those related to the fundamental ideas or beliefs of each group, those which are regarded as absolute truths, or sacred truths which the other simply does not have the right to consider or judge. An example of this sort of tolerance may be evidenced by the situation of the Jewish community in Eastern Europe prior to the Second World War, where there is evidence that coexistence with the Jewish community was tolerated because of the economic benefit and stability attained due to the business activities of many members of that community. This tolerance functioned relatively well as long as religious beliefs and practices were not discussed or expressed in the presence of non-Jews. In other words, coexistence with the Jewish people was accepted as long as religion was not part of the relation.

In the third and final degree of tolerance, that which compares with what we have termed positive tolerance, we can find not only coexistence but also openness to thoughtful questioning and critique between various groups in a given community. This degree of tolerance is the one that most closely approximates a vision of recognition and respect for the other. To speak of a third degree or level of tolerance where inter-groupal critique and questioning of deeply held convictions is accepted requires a priori acceptance that there are and should be a variety of worldviews and belief systems none of which necessarily is in possession of the absolute truth.

The first and second degrees of tolerance both include an implicitly passive vision of tolerance where one permits coexistence with the other as long as it does not require any real or deep interaction with that other about that which is really important. On the other hand, the third level is explicitly identified as an ethical principle insofar as it supports, or even requires, the open dialogue and reflection about ideas and commitments. This openness to examination and critique by outsiders is related to a constructive view of human beings that arises, as Mill argued, whenever discussion and argument occurs between distinct members of society. In this instance there is no imposition of ideas, nor is there any single correct, or valid worldview (Mill, 1999: pp. 56-74). The truth is not something that we have coming to the table. Rather, it is something we come to through the practice of open dialogue and the debate amongst equally potentially valid forms of understanding and being in the world. Therefore, it is important to understand the difference between truth-claims and validity-claims. A truth-claim refers to real subjectivity wherein every person judges the truth of a given claim in accordance with her knowledge, traditions, and background. In contrast, a validity-claim refers to what is achieved through intersubjective relations. That is, it does not take into account one person's point of view, but rather requires a shared and accepted opinion reached through discussion of different ideas. In this sense, each person's point of view about reality is taken into account during the process of discussion and for this reason we refer to claims of reliability as based on intersubjective relations.

This is not to say that positive tolerance requires the homologation of all different points of view into just one general point of view good for everyone. Rather, this understanding allows for a constructive process wherein each of the implicated parties or groups is invited to consider themselves and their values within the context of an encounter with the other. Tolerance exists when differences are considered as crucial and when the manner in which we react to those differences determines whether we are under conditions of positive or negative tolerance (Dees, 1997: p. 148). Thus, within positive tolerance the possibility for the existence and even desirability of dissent presents itself. This is a key element in improving dialogue by raising divergent opinions in a constructive, if critical, atmosphere. 
Then, as can be seen, positive tolerance is a potential solution to the standard interpretation of tolerance in its strictly negative dimension. This is especially true when we consider that concerns for individual freedom and the necessity for coexistence within contemporary societies demand that we find a better option than merely putting up with that, which is not in conformity with our own beliefs and practices. Positive tolerance thus presents us with a way to understand and live within these spaces characterized by diversity in terms of worldviews and practices. With this tool the space where two persons or various groups find themselves together becomes a space where discourse, recognition and respect for the value of the other as a human person is made possible while at the same time the cultural dimensions which permeate the way that we see ourselves and others can be accommodated within a framework of responsibility to take into account that human beings are irremediably diverse and inevitably social. We must relate with one another. This step in favor of positive tolerance signifies a conscious decision to understand that the pretension for truth in which we live and understand ourselves can be transformed into a search for claims of reliability.

However, the change from a negative tolerance to a positive one cannot be achieved unless we accept the fact that different opinions may be valid even when they express something I oppose or find unfamiliar. This arises the question of how could we do that? How do we reinforce the attitude to respect and recognize the other? It seems that the difficult issue here is to commit ourselves to recognizing, respecting, listening and considering perspectives we find foreign as equally valid. I propose that this openness to the other could be reached through a hermeneutical approach in which the recognition of the other plays an important role. Thus, I suggest that in order to make the transition between a negative tolerance to a positive one, we should consider the hermeneutic dialogue proposed by Gadamer. This approach will be analyzed in the next part of the present text.

\section{Recognition and Dialogue as the Process Required to Pass from a Negative Tolerance to a Positive One: Gadamer's Hermeneutics as an Ethical Approach to the Concept of Toleration}

It is clear that positive tolerance demands an active attitude of respecting, listening and recognizing others perspectives and visions as worthy, in the sense that they might have something to tell us ${ }^{1}$. Following this assumption, I introduce the philosophical hermeneutics proposed by Gadamer as an ethical approach to reconsider the concept of toleration in order to reinforce its positive notion. As we have seen, the concept of tolerance has been used as a way to establish political order in the sense of limiting the power between political and religious institutions. However, my attempt to analyze it through an ethical perspective is in order to reinforce the notion of tolerance as practical virtue, which means that there should be a commitment to act in a tolerant way in our daily lives. My attempt here is that once we have thought in tolerance as a virtue, we can think about its political implications, but gaining the attitude of commitment to its practice while we recognize the other as a valuable interlocutor. This commitment will also emphasize the difference between a negative practice of toleration, recognized as indifference, and a positive one based on dialogue, respect and recognition.

Without starting a dissertation on the meaning of ethics, I advance here that the importance of an ethical approach of tolerance refers to the sense that ethics gives to human understanding of his life as individual and as part of a community. Nevertheless, a constant dilemma in ethics is how to resolve the gap between the theoretical reflection of some values as justice and liberty, and how do these values are used regarding specific situations and circumstances. In this sense, I based my reflection on Gadamer's theory of a philosophical hermeneutics because it promotes an ethical perspective of dialogue which, I think, will serve to reinforce the commitment to dialogue proper of a positive tolerance. Gadamer's reflection about ethics agrees with his notion of hermeneutics, in the sense that for him ethics imply more than just a theoretical knowledge about values and virtues, but in fact how do we translate them to common situations that we face every day” (Gadamer, 2001: p. 117); in other words, that the moral knowledge about what is considered as a virtuous life and worthy to live, has an implication in our daily behavior. At this point, Gadamer highlights the importance of ethical knowledge as a form of praxis, an assumption that could be related with his idea of experience and dialogue.

Attempts have been made to clarify the concept of hermeneutics, however I am following Gadamer's reflection because: firstly, he proposes dialogue and language to underpin the attitude of questioning, reflection and

\footnotetext{
${ }^{1}$ Here, I want to take distance from the view that qualifies tolerance as the act of just respecting others. Respect could be seen as a bottom value needed to support an attitude of tolerance. In a sense, tolerance implies a minimum of respect so that it helps us to refrain for doing something. However, if tolerance is only understood as an action of respect, it could lead to a negative and passive attitude of tolerance, which implies the rejection of the possibility of dialogue and comprehension between different ideas/people/groups.
} 
understanding of the world and the human being, but his idea of dialogue implies a reciprocal recognition between people who participate in that dialogue; secondly, Gadamer considers the historicity of everyone is part of a constant dialogue that reinforces the need to assure both: the importance of others, and the role of circumstances that shape how do we understand every specific moment; and finally, he proposes a practical approach to philosophy and hermeneutics, in the sense that philosophy has to refer to the practical life of the human being, while hermeneutics should be considered as the process through which this phronesis arises. In Gadamer's hermeneutics, the importance is not settled in the result of understanding what an object is, but mainly in the process of understanding; in other words in the experience of understanding (Grondin, 2003: p. 42).

As we have seen, the idea of attempting to understand the other and myself through dialogue requires an element of interpretation, in the sense not only to translate the meaning of words but to try to achieve understanding about the circumstances that surround those words. In a sense, words are not separated from the context from which they arise. Hence, following Gadamer's arguments, I suggest that a hermeneutical approach comes from the sense of awareness that there is not a unique notion of truth that could explain the world and the human being.

According to Gadamer, the philosophical hermeneutics emphasizes a critical questioning of the world because it is conceived as a whole that is under interpretation. Then, language and dialogue become the tools to interpret the world, while this interpretation gives sense to our actions. For Gadamer, the importance of hermeneutics as a process is not only based on the analysis of objects or facts, but it is also found within the process of questioning and analyzing. Gadamer argues that I actually start to question myself by questioning and attempting to understand something or someone else; therefore, the act of questioning demands from us a type of responsibility (Dutt, 1998: p. 32); this responsibility is understood as a demand to realize that we could comprehend ourselves by the fact of recognizing the other. The experience of understanding depends on our own predisposition to be questioned by other's view and dialogue.

In this sense Gadamer proposes the hermeneutic circle as a process for experiencing and understanding. The hermeneutic circle implies to be become aware that when we are part of a moment of dialogue that also involves dialoguing with other, we must recognize that we, both, are also part of the world of this person who is part of this moment of recognition (Gadamer, 2007: pp. 244-245). This process acknowledges that dialogue is required between me and the other because through this dialogue arises the recognition of the other; a recognition that takes into account the individual as a being but also with his historicity, that means with an historical context that he brings up at the moment of dialoguing and influences his perceptions of the world ${ }^{2}$. This dialogue also implies that we consider how shall we affect and influence each other by our interactions. Thus, to recognize the other implies to realize how I am also influenced by the way he perceives me, himself and the world; to comprehend him is also a way to comprehend myself.

Besides, for Gadamer, the hermeneutic dialogue also means to realize that there is always something that escapes from our reasoning. As we found ourselves in front of another, we become aware of the limits of our own thought. This always happens in an authentic dialogue. According to Gadamer, through this authentic dialogue we get closer to the truth as we give up to inadequate ideas about the world and ourselves (Dutt, 1998: p. 44). Even when these ideas are inadequate or incomplete, they serve as a way to understand the world and the sense of our lives in that world. Then, the experience of dialogue and recognition gains importance as it helps us to become aware of our own prejudgments. Here, prejudgments are taken as incomplete ideas that would be complemented and proved through the criticism and dialogue from perspectives and thoughts different than mine (Gadamer, 2007: p. 237).

In addition, this process demands us to recognize that encountering the other could lead to a wider comprehension through the acceptance of other horizons that explain the world. For Gadamer, once we recognize the relevance of different horizons, we enhance our scope of understanding. In this moment, we will be part of a fusion of shared horizons (Gadamer, 2007: p. 377). This fusion of horizons is a moment of continuous movement, in the sense that everything (even us) is subject of a constant interpretation. In order to accomplish this interpretation, we need a positive tolerance as we part of a permanent exercise of facing something foreign for us, but something that we need to comprehend as part of our moral understanding of the world.

At this point, experience plays an important role as a moment of dialogue and encounter. To dialogue with someone means also the experience of being with someone. An authentic dialogue means that you do not know

${ }^{2}$ For Gadamer, human beings are also historical beings, in the sense that their historical backgrounds also define themselves and the way they perceive the world. 
in advance the final conclusion; besides, it means that at the end of the encounter there is always something that is not totally understood. However, in a sense, this experience of dialogue and interpretation searches for a kind of agreement, even when there is the awareness of things that will rest unsolved. This search for agreement denotes a will of understanding, at least in a minimum set of topics ${ }^{3}$. This reinforces the demand of a critical reflection about an incomplete truth. There is always something to be solved, understood or criticized, and this can only be accomplished through experiencing dialogue with the other (Dutt, 1998: pp. 61-62).

The question, then, is how we improve this moment of authentic dialogue with someone that behaves in a different, even offensive, way from us. In this sense, we can recall Gadamer's arguments about the importance of recognition as a way to understand the other and ourselves, taking into account the limitations that everybody has with their own prejudgments. Even when that does not imply a specific process, it reinforces the attitude of questioning what is being considered as a truth. The criticism here is that this could be confused as the idea of accepting everything or, in other words, tolerating everything. Nevertheless, Gadamer's theory takes distance of this kind of relativism, in the sense that he proposes a philosophical approach that implies the dialogue with someone. If we take as valid any assumption, we are rejecting the moment of dialogue and interpretation; therefore, we are avoiding any hermeneutical encounter. In addition, Gadamer's theory refers to a practical vision in the sense that understanding the other means experiencing the fact of living with the other.

Here is where I see the connection between Gadamer's hermeneutical approach and positive tolerance, in the sense that tolerance demands the recognition of different and divergent ideas as part of intersubjective relationships. Positive toleration gives us the opportunity of raising diverse opinions in a critical atmosphere, where the goal is not the imposition of any thought but the understanding between each other, in a broad sense. If we propose tolerance as a political virtue it is because through dialogue we develop a sense of community in a moral perspective, as a form of living with others. Further, tolerance reinforces the sense of respect and recognition within plural societies, which find valuable different and diverse point of views.

Nevertheless, if we are to consider tolerance as a political virtue, then it is important to analyze the way in which tolerance implies something different as the usual use of the term. Following Marcuse argument, commonly the term of tolerance is misused as a form to support authoritarian regimes instead of straightening the value of difference and recognition among diversity. These assumptions question the limits that toleration should have in order to avoid a misunderstanding and misuse of the term. Those perspectives cannot be ignored and, therefore, they will be analyzed as the next part of this text.

\section{Facing the Threshold: The Need of Tolerance and Intolerance}

Even when tolerance is considered as a virtue needed to develop and sustain a democratic society where there arises the debate between different opinions and ideas (Camps, 1996), this virtue could be corrupted. During 1968, Herbert Marcuse pointed out that tolerance could be used, by a dominant group, as a form to sustain its point of view and its position of power (Marcusse, 1968). This could lead to supporting some abuses and violations against human dignity as part of reinforcing a higher ideal as seek for security ${ }^{4}$; thus, it would mean that the concept and the practice of tolerance could be corrupted, leading to a false notion of tolerance. This false tolerance strengthens the attitude of indifference and conformity unless the harm is done to me or my beloved ones. Besides, it implies an attitude of conformity which also depends of how safe we feel in our society or community. The risk is that in assuring a minimum condition of security, we can give up to refrain and stop some attitudes and behaviors that will be questioned in other circumstances. "[I]f we establish the right to live as our main and principal right there is the risk of, by the end of the day, considering it as the only one" (Arteta, 2001: p. 1999). In this scenario, tolerance is not considered as a political virtue, but as an instrumental attitude that reinforces authoritarian practices. This should lead us to understand the limits settle to toleration, and then, to rethink whether the relation and limits between tolerance and intolerance are adequate.

Commonly, the limits that are conceived to the fact of tolerating something are: firstly, the intolerance with the intolerant; and secondly, the intolerance to harm others, even if it implies a physical or a moral harming. Both limits are related to each other, in the sense that they refer to the social condition of tolerance. The fact of not tolerating an intolerant is because he is rejecting for others what he claims valid for him (Thiebaut, 1999: p.

\footnotetext{
${ }^{3}$ Even though, it does not negates the possibility of dissent.

${ }^{4}$ In recent times, Mexico has been facing a huge controversy between the military forces focused on the war against drug dealers and criminal organizations, and the accusations of citizens that were abused by soldiers of the Mexican army (Mosso, 2009).
} 
182). He claims for tolerance from other people, as he behaves in an authoritarian way among them. This emphasis in the social role of tolerance leads to the second limit of tolerance that is avoiding harming others. An authoritarian behavior tends to surpass above someone's freedom of conscience and expression (Thiebaut, 1999: p. 183). The refraining of tolerance due to avoiding harming others implies a social perspective because it demands to have in mind the presence of others. Obviously, the degree of importance assigned to the presence of others depends on the types of tolerance that have described before. Furthermore, what links both limits of tolerance is the absence of respecting the other and recognizing him as an individual who is able to find his own form and sense to live or, in other words, his own ethos.

Nevertheless, the criticisms arose to this conception of the limits of tolerance start when a political institution defines who is considered as an intolerant one (Arteta, 2001: p. 182), because through these acts, the government in power could diminish the presence of divergent thoughts within the political debate. Precisely, this is the starting point to the criticism to tolerance brought by Slavoj Žižek. According to Žižek, nowadays the tolerance that prompts in liberal democracies actually enclosed a specific way of life in which tolerance is valued unless the difference within a society implies a risk to the model of democracy already established. Then the practice of this kind of tolerance could be identified as a repressive one if something menaces this specific arrangement (Žižek, 2007). To Žižek, the tolerance supported as part of a democratic regime tends to enhance and idea of homogenization behind values of consumption that will help to reproduce one model of thought: to only guarantee the satisfaction of my needs and the feeling of security.

This attitude of conformity and consumption is the object of Žižek's criticisms, because it defines political negotiations in economical terms, wiping out any difference that will put in risk the economical system that characterizes the global capitalism (Žižek, 2007: p. 59). Here, a false tolerance is presented as a negative one, in the sense that it permits the existence of difference while important issues about politics and economics are not questioned. The risk here is that this kind of tolerance could prompt violent behavior if the groups in the power feel any kind of menace; usually, if this happens, sovereign powers allow infringing the limits of what is tolerable as a way to defend its own powerful position. Thus, this false tolerance is allowing the emergence of authoritarian attitudes and totalitarian regimes. Then, security becomes the main column of sovereign power. This encircles the idea of tolerance to the right to live, with the implications that it could be seen as the only right that is worthy to defend. In this sense, tolerance is guaranteed just as a way of living but not in a social standard of recognizing and valuing differences. The role of tolerance as a political virtue would be then questioned as whether it really functions as its meant to be, or if it just an alibi to guarantee an status quo.

Žižek's solution considers the defense of intolerance as a form to break up with the false tolerance and a way to bring up the ideals proper of a positive tolerance, in order to recover the ideals of recognition and community. In this sense, the conception of the limits of toleration starts to be depicted more as a threshold where tolerance and intolerance are together, as tolerance also needs the assistance of intolerant attitudes as a way to prevent its own corruption. Finally, if we consider tolerance as a political virtue, we must be aware that it does not represent the wiping out of intolerance; on the contrary, it implies that both attitudes represent both sides of the same coin, demanding from us to be more critical in the way both are used and presented in common life.

\section{Living in the Threshold}

As a conclusion, tolerance was conceived, since the beginning, as an ideal that reinforces social relations and the life in community. Besides, it also implies a life of practicing in the attitude of being tolerant with difference; accepting that differences are part of societies and differences are what make societies alive entities. Through this text I have consider different approaches to tolerance as a form to reinforce the conception of a positive understanding of the term. However, in order to reinforce its social dimension, I have exposed some of the main points of the philosophical model of hermeneutics proposed by Gadamer that I believe will serve to this purpose. Furthermore, to understand tolerance means to understand the limits of what is tolerable, which questions the usage of toleration nowadays. Even when toleration is a value and a political virtue promoted within democratic societies, sometimes it is misused as a mean of power, corrupting the ideals of liberty, respect and recognition that give it its sense.

Tolerance is mainly a social virtue that implies the relation with others. To understand toleration as a virtue means to practice it in daily life. Toleration is meant to be a political virtue in heterogeneous societies; nevertheless, before becoming a political virtue it should be prompted as a moral one in the sense that it should be 
practiced daily by the individuals that are part of a society. Then, in order to promote this practice, we need firstly to cultivate people in the attitude of being tolerant. This will required the acceptance of the validity of claims instead of taking them as absolute truths. It also demands the acknowledgement of tolerance as the experience of understanding the world and ourselves in a moment of dialogue among other people.

\section{References}

Arteta, A. (2001). Verdadera y Falsa Tolerancia. In F. J. Peña Echeverría (Eds.), Ética para la sociedad civil (pp. 177-200). Spain: Consejo Social de la Universidad de Valladolid.

Camps, V. (1996). Virtudes Públicas. Madrid: Editorial Espasa Calpe.

Dees, R. (1997). The Justification of Toleration. In M. A. Razavi, \& D. Ambuel (Eds.), Philosophy, Religion, and the Question of Intolerance (pp. 134-156), New York: State University of New York.

Dutt, C. (1998). En conversación con Hans-Georg Gadamer. Madrid: Tecnos.

Gadamer, H. (2001). Sobre la posibilidad de una ética filosófica. In Antología (pp. 117-133), Salamanca: Sígueme.

Gadamer, H. (2007). Verdad y Método. Salamanca: Sígueme.

Grondin, J. (2003). Introducción a Gadamer. Spain: Herder.

Marcuse, H. (1968) “La tolerancia represiva”. In Convivium 27. April-Septembre.

Mill, J. S. (1999). On Liberty. Great Britain: Cambridge University Press.

Mosso, R. (2009). Acepta el Ejército 35 abusos en la lucha contra el narco. Milenio Diario, Primera Plana. http://www.milenio.com/node/253297

Sassier, P. (2002). Tolerancia ¿para qué? Mexico: Taurus.

Thiebaut, C. (1999). De la tolerancia. Madrid: Visor.

Todorov, T. (1993). Frente al límite. Mexico: Siglo XXI.

Waldron, J. (1993). Rushdie and Religion. In Liberal Rights: Collected Papers 1981-1991 (pp. 134-142). New York: Cambridge University Press.

Žižek, S. (2007). En defensa de la intolerancia. Madrid: Sequitur. 